\title{
Serum Estradiol Level at Intensive Care Unit Admission and Mortality in Critically III Patients
}

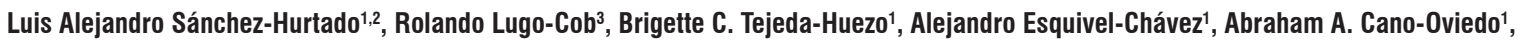 \\ Sergio Zamora-Varela', Saira S. Gomez-Flores ${ }^{1}$, Perla Arvizu-Tachiquin ${ }^{1}$, José A. Baltazar-Torres ${ }^{1,4}$
}

'Department of Critical Care Medicine, UMAE Specialties Hospital "Dr. Antonio Fraga Mouret” National Medical Center "La Raza”, Mexican Institute of Social Security (IMSS), ${ }^{2}$ Department of Critical Care Medicine, Instituto Nacional de Cancerología, SSA, ${ }^{4}$ Department of Critical Care Medicine, Instituto Nacional de Ciencias Médicas y Nutrición Salvador Zubirán, Mexico City, ${ }^{3}$ Department of Critical Care Medicine, UMAE Cardiology Hospital No. 34 Mexican Institute of Social Security (IMSS). Monterrey, Nuevo León, México

\section{Abstract}

Context: It has been observed that sex hormones may play a role in inflammatory processes and mortality of critically ill patients. Aims: The aim was evaluated the relationship between serum estradiol level at Intensive Care Unit (ICU) admission and mortality of critically ill patients. Settings and Design: This study was a prospective cohort conducted in one mixed ICU. Subjects and Methods: In heterogeneous group of critically ill patients admitted to the ICU, we measured serum estradiol at admission time. Statistical Analysis Used: The discrimination to predict mortality of serum estradiol level was assessed by the receiver-operating curve (ROC) curve and its association with mortality by logistic regression analysis. Results: We included 131 patients, $57.3 \%$ of which were male. The serum estradiol level measured at ICU admission was significantly higher in nonsurvivors than in survivors: 116 versus $67.2 \mathrm{pg} / \mathrm{mL}$, respectively $(P<0.0001)$. The area under the ROC of serum estradiol level to predict mortality was $0.74(P<0.0001)$. Serum estradiol level $\geq 97.9 \mathrm{pg} / \mathrm{mL}$ had sensitivity of $60 \%$, specificity of $90 \%$, positive predictive value of $64 \%$, negative predictive value of $88 \%$, positive likelihood ratio of 6 , and negative likelihood ratio of 0.44 , for predicting mortality. In multivariate analysis, it had relative risk of $6.47(P=0.002)$ for ICU mortality. Conclusions: The serum estradiol level is elevated in critically ill patients, regardless of gender, especially in those who die. It has good discriminative capacity to predict mortality, and it is an independent risk factor for death in this group of patients.

Keywords: Critical illness, estradiol, mortality, outcome

\section{INTRODUCTION}

During acute illness, the risk of death depends mainly on the severity of the disease, previous health status of the patient, and how he/she responds to disease or injury. ${ }^{[1]}$ In the past decade, some studies have evaluated the impact of gender and hormonal status on mortality of patients with different acute conditions and found that hormones may play a role that can influence the outcome of critically ill patients. ${ }^{[1-5]}$

During stress, gonadal synthesis of estradiol is inhibited by Class I cytokines and tumor necrosis factor alpha, whereas there is an activation of the peripheral estradiol production by enzyme aromatase in adipose tissue, regardless of gender of the patients. ${ }^{[1-3,6]}$ Estradiol causes changes in the immune response such as inhibition of the action of T-cells and activation of B-cell and macrophages inducing the production of interleukin 2 and interferon- $\alpha$, mainly. ${ }^{[7,8]}$

\begin{tabular}{|l|l|}
\hline \multicolumn{3}{|c|}{ Access this article online } \\
\hline Quick Response Code: & Website: \\
& www.ijccm.org \\
& \\
\end{tabular}

Different studies in animal models have shown that changes in the immune response induced by estradiol produce an inflammatory response and modify the survival.$^{[3,5-8]}$ In humans, some authors have shown that, in clinical settings such as trauma or surgical patients, the increase in the serum level of estradiol was associated with increased severity of disease and mortality, regardless of the gender of patients, and was proposed as a tool for predicting mortality. ${ }^{[1,3,5,8-10]}$ All this evidence has been documented in specific groups of patients

Address for correspondence: Dr. Luis Alejandro Sánchez Hurtado, Department of Critical Care Medicine, UMAE Specialties Hospital "Dr. Antonio Fraga Mouret” National Medical Center "La Raza", Mexican Institute of Social Security (IMSS). Mexico City, Mexico. E-mail: lashmd@gmail.com

This is an open access article distributed under the terms of the Creative Commons Attribution-NonCommercial-ShareAlike 3.0 License, which allows others to remix, tweak, and build upon the work non-commercially, as long as the author is credited and the new creations are licensed under the identical terms.

For reprints contact: reprints@medknow.com

How to cite this article: Sánchez-Hurtado LA, Lugo-Cob R, Tejeda-Huezo BC, Esquivel-Chavez A, Cano-Oviedo AA, Zamora-Varela S, et al. Serum estradiol level at Intensive Care Unit admission and mortality in critically ill patients. Indian J Crit Care Med 2018;22:96-9. 
and used different cutoffs of serum estradiol levels to predict mortality. The aim of this study was to evaluate the capacity of serum estradiol level, measured at Intensive Care Unit (ICU) admission, and to predict mortality in a heterogeneous group of critically ill patients.

\section{Subjects and Methods}

We conducted a prospective, transversal, observational, analytical, and single-center study in patients admitted to the ICU between June $1^{\text {st }}$, and December 31 ${ }^{\text {st }}, 2015$. We included patients $>18$ years old, of both genders, and who signed informed consent to participate in the study. Patients with brain death, pregnancy, or puerperium were excluded from the study. We recorded the following demographic and clinical variables: age, sex, comorbidities, Carlson's index, Acute Physiology and Chronic Health Evaluation (APACHE II) score, ${ }^{[1]]}$ Sequential Organ Failure Assessment (SOFA) score, ${ }^{[12]}$ patient type (medical and surgical), sepsis, vasopressors, inotropes, renal replacement therapy, mechanical ventilation, length of mechanical ventilation, tracheostomy, and length of stay in the ICU. The serum estradiol level was measured at ICU admission. For this, a sample of $3.5 \mathrm{cc}$ of venous blood was taken by direct puncture or through a central venous catheter in patients who have this device. The sample was placed in a tube with ethylenediaminetetraacetic acid and centrifuged. The serum estradiol level was determined by immunofluorescence in free of hemolysis serum on a IMMULITE $2000^{\circledR}$ equipment. The main outcome was ICU mortality. The research protocol was reviewed and approved by the Local Research Committee (registration number R-2015-3501-102).

\section{Statistical analysis}

Descriptive statistics are used for data presentation. Numeric variables with normal distribution are expressed as a mean \pm standard deviation and those with free distribution are expressed as medians with interquartile range (IQR). The distribution of the data was determined by the Kolmogorov-Smirnov's test. Nominal variables are expressed as a percentage. Quantitative variables were compared using the Student's $t$-test or Mann-Whitney's U-test, as appropriate. Nominal variables were compared using the Chi-square test or the Fisher's exact test. The discriminative capacity of serum estradiol level for predicting mortality was evaluated by the area under the receiver-operating curve (ROC) curve. The identification of serum estradiol level cutoff associated with mortality was performed by ROC curve. The serum estradiol level with the highest sensitivity and specificity for discriminating mortality was identified using Youden's index. The positive predictive value and negative predictive value (NPV) were calculated using the appropriate serum estradiol level cutoff. The association between serum estradiol level and mortality was assessed by multivariate logistic regression analysis. In all cases, $P<0.05$ was considered statistically significant. The data analysis was performed using the Statistical Package for the Social Sciences version 20.0 for Windows (SPSS Statistics 20.0 for Windows, Armonk, NY, USA).

\section{RESULTS}

One hundred thirty-one patients were included, 75 (57.3\%) were males and $56(42.7 \%)$ were females. The mean age was $48.9 \pm 17.2$ years. There were $70(53.4 \%)$ patients admitted by surgical conditions and $46(35.1 \%)$ patients were septic. At least one comorbidity was present in 108 (82.4\%) patients, of which the most frequent was hypertension. The overall ICU mortality rate was $22.9 \%(n=30)$.

Patients were divided for comparison per the clinical condition at ICU discharge. In nonsurvivors, a higher proportion of subjects had diabetes mellitus $(P=0.002)$ and sepsis $(P=0.001)$, higher Charlson's index $(P=0.01)$, and higher APACHE II $(P=0.02)$ and SOFA $(P=0.001)$ scores at ICU admission. In this group, the use of vasopressors $(P<0.0001)$ and mechanical ventilation $(P=0.02)$ were more frequent, and the length of mechanical ventilation was higher $(P=0.001)$. Other results are shown in Table 1.

In the survivors, the serum estradiol level had a median of 67.2 (IQR: 43.45-79) $\mathrm{pg} / \mathrm{mL}$, whereas in nonsurvivors was 116 (IQR 64.4-161) $\mathrm{pg} / \mathrm{mL}$. This difference was statistically significant $(P<0.0001)$. There was no significant difference in mortality according to gender $(21.3 \%$ in man vs. $25 \%$ in women, $P=0.62$ ). In addition, we found a higher serum estradiol level in septic patients (median 82.6 [IQR 69.23-145.25] pg/mL), compared to nonseptic patients (median 58.1 [IQR 43.1-77.4] $\mathrm{pg} / \mathrm{mL})$, this difference was statistically significant $(P<0.0001)$. Other variables such as gender, age of women (older or younger than 45 years), and type of patient (medical or surgical) were not statistically different between groups.

Discriminative capacity for predicting mortality of serum estradiol level is shown in Figure 1. The area under the ROC curve was 0.74 (95\% confidence interval [CI] $0.63-0.86)$ and $P<0.0001$. The best serum estradiol level cutoff for predicting

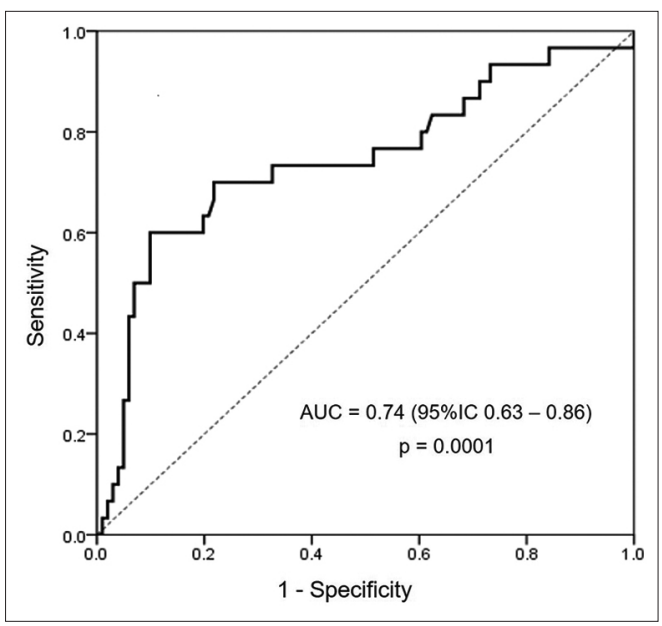

Figure 1: Receiver-operating curve for predicting mortality of serum estradiol level in critically ill patients 


\begin{tabular}{|c|c|c|c|c|}
\hline & All & Survivors & Non-survivors & $P$ \\
\hline & 131 & 101 & 30 & \\
\hline Male, $n(\%)$ & $75(57.3)$ & $59(58.4)$ & $16(53.3)$ & $0.621^{+}$ \\
\hline Age (years) & $48.9 \pm 17.2$ & $47.8 \pm 16.9$ & $52.8 \pm 18.1$ & $0.158^{*}$ \\
\hline Charlson's index & $1(0-1)$ & $1(0-1)$ & $1(0.75-3)$ & $0.016^{\$}$ \\
\hline \multicolumn{5}{|l|}{ Comorbidities, $n(\%)$} \\
\hline Hypertension & $56(42.7)$ & $41(40.6)$ & $15(50)$ & $0.36^{+}$ \\
\hline Diabetes mellitus & $51(38.9)$ & $33(32.7)$ & $18(60)$ & $0.002^{+}$ \\
\hline COPD & $10(7.6)$ & $7(6.9)$ & $3(10)$ & $0.69^{\circ}$ \\
\hline Chronic renal disease & $6(4.6)$ & $5(5)$ & $1(3.3)$ & $1^{\mathrm{o}}$ \\
\hline Hipotiroydism & $3(2.3)$ & $1(1)$ & $2(6.7)$ & $0.13^{\circ}$ \\
\hline \multicolumn{5}{|l|}{ Type of patient, $n(\%)$} \\
\hline Medical & $61(46.6)$ & $45(44.6)$ & $16(53.3)$ & $0.397^{+}$ \\
\hline Surgical & $70(53.4)$ & $56(55.4)$ & $14(46.7)$ & \\
\hline Sepsis, $n(\%)$ & $46(35.1)$ & $28(27.7)$ & $18(60)$ & $0.001^{+}$ \\
\hline APACHE II score & $14.2 \pm 6.7$ & $13.4 \pm 6.3$ & $17 \pm 7.3$ & $0.008^{*}$ \\
\hline SOFA score & $6(3-9)$ & $4(2-8)$ & $7(5-10.5)$ & $0.001^{\$}$ \\
\hline Serum estradiol level $(\mathrm{pg} / \mathrm{mL})$ & $70(48-91.2)$ & $67.2(43.5-79)$ & $116(64.4-161)$ & $0.001^{*}$ \\
\hline Vasopressors, $n(\%)$ & $69(57.2)$ & $42(41.6)$ & $27(90)$ & $0.0001^{+}$ \\
\hline Inotropics, $n(\%)$ & $15(11.5)$ & $12(11.9)$ & $3(10)$ & $1^{\mathrm{o}}$ \\
\hline Renal replacement therapy, $n(\%)$ & $6(4.6)$ & $4(4)$ & $2(6.7)$ & $0.62^{\circ}$ \\
\hline Mechanical ventilation, $n(\%)$ & $108(82.4)$ & $79(78.2)$ & $29(96.7)$ & $0.02^{+}$ \\
\hline Length of mechanical ventilation (days) & $1(1-6)$ & $1(0.75-1)$ & $4(1.5-10.5)$ & $0.001^{\$}$ \\
\hline Lenght of ICU stay (days) & $4(2-8)$ & $4(2-7)$ & $4(1-11)$ & $0.689^{\$}$ \\
\hline Mortality, $n(\%)$ & $30(22.9)$ & - & - & - \\
\hline
\end{tabular}

COPD: Chronic obstructive pulmonar disease; APACHE: Acute physiologic and chronic health evaluation; SOFA: Sequential organ failure assesment; ICU: Intensive Care Unit. *Student's $t$-test; ${ }^{\$}$ Mann-Whitney U test $;{ }^{+} \chi^{2}$ test; ${ }^{\circ}$ Fisher's exact test

mortality was $97.9 \mathrm{pg} / \mathrm{mL}$. It had sensitivity of $60 \%$, specificity of $90 \%$, positive predictive value of $64 \%$, NPV of $88 \%$, positive likelihood ratio of 6 , and negative likelihood ratio of 0.44 .

In the multivariate logistic regression analysis, serum estradiol level $\geq 97.9 \mathrm{pg} / \mathrm{mL}$ (relative risk [RR]: $6.47,95 \%$ CI: $1.97-21.19, P=0.002$ ) and use of vasopressors (RR: 5.82 , 95\% CI: $1.38-24.63, P=0.02$ ) were identified as independent risk factors for death in our patients [Table 2].

\section{Discussion}

This study evaluated the capacity of serum estradiol level (measured at ICU admission) to predict mortality in a heterogeneous cohort of critically ill patients. We found that the serum estradiol level at ICU admission was higher in patients who die and that had no significant differences between genders. We also found that serum estradiol level is independently associated with ICU mortality, that it has good capacity to identify patients at increased risk for death, and that the cutoff of $97.9 \mathrm{pg} / \mathrm{mL}$ had the best sensitivity and specificity to predict mortality.

May et al..$^{[10]}$ found that serum estradiol level $>100 \mathrm{pg} / \mathrm{mL}$ in surgical patients with trauma was associated with increased mortality. Dossett et al. ${ }^{\left[{ }^{[9}\right.}$ reported that a serum estradiol level $>50 \mathrm{pg} / \mathrm{mL}$ had a good discriminative capacity to predict mortality in patients with trauma. Kauffmann et al. ${ }^{[3]}$ found

\begin{tabular}{|c|c|c|c|}
\hline & RR & $95 \% \mathrm{Cl}$ & $P$ \\
\hline Diabetes mellitus & 2.82 & $0.89-8.94$ & 0.08 \\
\hline Charlson's index & 1.19 & $0.83-1.73$ & 0.35 \\
\hline Sepsis & 1.57 & $0.47-5.29$ & 0.46 \\
\hline APACHE II score & 10.4 & $0.94-1.16$ & 0.44 \\
\hline SOFA score & 1.01 & $0.84-1.22$ & 0.88 \\
\hline Serum estradiol leve $1 \geq 97.9 \mathrm{pg} / \mathrm{mL}$ & 6.47 & $1.97-21.19$ & 0.002 \\
\hline Vasopressors & 5.82 & $42(41.6)$ & 0.02 \\
\hline Mechanical ventilation & 3.73 & $0.29-47.11$ & 0.31 \\
\hline Length of mechanical ventilation & 1.06 & $0.96-1.17$ & 0.26 \\
\hline
\end{tabular}

RR: Relative risk; 95\% CI: 95\% confidence interval; APACHE: Acute physiologic and chronic health evaluation; SOFA: Sequential organ failure assessment; Hosmer-Lemeshow $\chi^{2}: 5.97 ;$ P: 0.65

that serum estradiol level $>67 \mathrm{pg} / \mathrm{mL}$ in surgical patients with trauma had good discriminative capacity to predict mortality, with area under the ROC curve of 0.64 (95\% CI 0.59-0.68), and that it was associated with mortality, with RR 1.3 (95\% CI 1.1-1.5). In addition, Kauffmann et al. ${ }^{[3]}$ did serial measurements of serum estradiol level and found that, those patients who haved changes from baseline, have an increased risk for death. Finally, Lu et al. ${ }^{[5]}$ found in patients with acute pancreatitis that nonsurvivors had a significantly higher serum estradiol level than survivors (206 vs. 39 pg/mL, respectively). 
The results of our study coincide with others previously published by other researchers. However, those studies were performed in patients with specific conditions. In our study, we included a heterogeneous population with medical and surgical conditions. In addition, in our population, septic patients had a significantly higher serum estradiol level than nonseptic patients.

Some authors ${ }^{[1,3,13]}$ have described an impact of gender on the outcomes in critically ill patients, placing the female gender as a risk factor for increased mortality and other complications. However, we do not find differences in mortality between genders, as reported in various studies. ${ }^{[1,9,10]}$

The strengths of this study include its prospective nature, its conduction in a heterogeneous population, and its confirmation that the increase in the serum estradiol level at ICU admission is associated with increased risk for death, regardless of the gender of the patients, the diagnosis, and the severity of the illness.

The study has some limitations: it was performed in a single center, the sample size is limited, we measured the serum estradiol level only at UCI admission, and we do not follow survivors after ICU discharge.

\section{Conclusions}

The serum estradiol level is increased in critically ill patients, regardless of gender, especially in those who die. It has good discriminative capacity to predict mortality and it is an independent risk factor for death in this group of patients.

\section{Financial support and sponsorship}

Nil.

\section{Conflicts of interest}

There are no conflicts of interest.

\section{REFERENCES}

1. Dossett LA, Swenson BR, Evans HL, Bonatti H, Sawyer RG, May AK, et al. Serum estradiol concentration as a predictor of death in critically ill and injured adults. Surg Infect (Larchmt) 2008;9:41-8.

2. Sakr Y, Elia C, Mascia L, Barberis B, Cardellino S, Livigni S, et al. The influence of gender on the epidemiology of and outcome from severe sepsis. Crit Care 2013;17:R50.

3. Kauffmann RM, Norris PR, Jenkins JM, Dupont WD, Torres RE, Blume JD, et al. Trends in estradiol during critical illness are associated with mortality independent of admission estradiol. J Am Coll Surg 2011;212:703-12.

4. Romo H, Amaral AC, Vincent JL. Effect of patient sex on Intensive Care Unit survival. Arch Intern Med 2004;164:61-5.

5. Lu CW, Liu LC, Hsieh YC, Yang LH, Chen RJ, Hsieh $\mathrm{CH}$, et al. Increased admission serum estradiol level is correlated with high mortality in patients with severe acute pancreatitis. J Gastroenterol 2013;48:374-81

6. Feng JY, Liu KT, Abraham E, Chen CY, Tsai PY, Chen YC, et al. Serum estradiol levels predict survival and acute kidney injury in patients with septic shock - A prospective study. PLoS One 2014;9:e97967.

7. Bengtsson AK, Ryan EJ, Giordano D, Magaletti DM, Clark EA.17betaestradiol (E2) modulates cytokine and chemokine expressionin human monocyte-derived dendritic cells. Blood 2004;104:1404-10.

8. Dossett LA, Swenson BR, Heffernan D, Bonatti H, Metzger R, Sawyer RG, et al. High levels of endogenous estrogens are associated with death in the critically injured adult. J Trauma 2008;64:580-5.

9. May AK, Dossett LA, Norris PR, Hansen EN, Dorsett RC, Popovsky KA, et al. Estradiol is associated with mortality in critically ill trauma and surgical patients. Crit Care Med 2008;36:62-8.

10. Knaus WA, Draper EA, Wagner DP, Zimmerman JE. APACHE II: A severity of disease classification system. CritCare Med 1985;13:818-29.

11. Vincent JL, Moreno R, Takala J, Willatts S, De Mendonça A, Bruining $\mathrm{H}$, et al. The SOFA (Sepsis-related organ failure assessment) score to describe organ dysfunction/failure. On behalf of the working group on sepsis-related problems of the European Society of Intensive Care Medicine. Intensive Care Med 1996;22:707-10.

12. Combes A, Luyt CE, Trouillet JL, Nieszkowska A, Chastre J. Gender impact on the outcomes of critically ill patients with nosocomial infections. Crit Care Med 2009;37:2506-11.

13. Heffernan DS, Dossett LA, Lightfoot MA, Fremont RD, Ware LB, Sawyer RG, et al. Gender and acute respiratory distress syndrome in critically injured adults: A prospective study. J Trauma 2011;71:878-83. 